\title{
The association between back pain and trunk posture of workers in a special school for the severe handicaps Kelvin CH Wong ${ }^{\dagger 1}$, Raymond YW Lee ${ }^{\dagger 2}$ and Simon S Yeung*†1
}

\author{
Address: ${ }^{1}$ Department of Rehabilitation Sciences, The Hong Kong Polytechnic University, Hong Kong and ${ }^{2}$ School of Human and Life Sciences, \\ Roehampton University, UK \\ Email: Kelvin CH Wong - kelvin_ernie@yahoo.com; Raymond YW Lee -r.lee@roehampton.ac.uk; \\ Simon S Yeung* - simon.yeung@polyu.edu.hk \\ * Corresponding author †Equal contributors
}

Published: 29 April 2009

BMC Musculoskeletal Disorders 2009, 10:43 doi:10.1 I86/147|-2474-10-43
Received: 25 June 2008

Accepted: 29 April 2009

This article is available from: http://www.biomedcentral.com/I47/-2474/I0/43

(C) 2009 Wong et al; licensee BioMed Central Ltd.

This is an Open Access article distributed under the terms of the Creative Commons Attribution License (http://creativecommons.org/licenses/by/2.0), which permits unrestricted use, distribution, and reproduction in any medium, provided the original work is properly cited.

\begin{abstract}
Background: The present study aims to determine the time spent in different static trunk postures during a typical working day of workers in a special school for the severe handicaps.

Methods: Eighteen workers with low back pain (LBP) and fifteen asymptomatic workers were recruited. A cross-sectional design was employed to study the time spent in different static trunk postures which was recorded by a biaxial accelerometer attached to the $T_{12}$ level of the back of the subjects.

Results: The results of ANCOVA revealed that subjects with LBP spent significantly longer percentage of time in static trunk posture when compared to normal $(p<0.05)$. It was also shown that they spent significantly longer time in trunk flexion for more than $10^{\circ}(p<0.0125)$.

Conclusion: An innovative method has been developed for continuous tracking of spinal posture, and this has potential for widespread applications in the workplace. The findings of the present investigation suggest that teachers in special schools are at increased risk of getting LBP. In order to minimise such risk, frequent postural change and awareness of work posture are recommended.
\end{abstract}

\section{Background}

Low back pain (LBP) is a prevalent and disabling workrelated musculoskeletal complaint encountered by a variety of industries. Epidemiological studies reveal that LBP is related to awkward postures, including trunk flexion with or without rotation [1-4], combined trunk flexion and manual lifting [5,6], frequent trunk bending [7] and prolonged static trunk flexion $[8,9]$. It has been shown that prolonged static trunk flexion may subject the spine to reduced activity of multifidus [10], provoke flexion relaxation phenomenon of the thoracic erector spinae resulting in the creep response of the lumbar spinal tissues [11-13], reduce the oxygenation of lumbar extensors due to the constant isometric contraction [14], and increase the intradiscal pressure [15].

Questionnaires and interviews, observation and direct measurements are commonly used techniques to document work postures at the workplaces. Bussmann et al. [16] stated that each of these approaches had its practical as well as methodological limitations. For instance, the use of questionnaires may give rise to low reliability and validity result [17] and the subjects may overestimate their postural exposure [18]. Observation method can only provide a rough idea of the time spent in certain postures [17] and it is only suitable for monitoring occupa- 
tions that normally confine in small working area. Although the inclinometer has shown to be reliable in measuring lumbar spine range of motion $[19,20]$, the temporal characteristics of the spinal movement cannot be documented. Advancement in technology has enabled the development of miniature accelerometers that can be suitably mounted onto the human body to record both static and dynamic human movement. Indeed, accelerometer has been used in measuring the trunk postures and movements in ergonomic research [21,22].

Working at floor level with stooped posture clearly constitutes a health risk for the musculoskeletal system of radish harvesting workers [23] and preschool workers [24]. To the authors' knowledge, no previous study has examined the risk factors of LBP for teaching staff in special schools although LBP is commonly reported in this workforce. Most students in the special school suffered from multiple contractures and deformities and are dependent on the teaching staff for carrying out the basic activities of daily living. Thus, the teaching staff members are required to spend much time in performing manual transfer and mat activities for the students in a stooped posture. These tasks may pose high risk to the development of cumulative trauma to the back. Based on the policy of the school, each teaching staff is expected to share the similar physical work load as students are evenly distributed into different classes based on their age and body weight. Thus, the work posture that they adopted during a typical working day might contribute to the development of LBP at the workplace.

The purpose of the present study was to develop an objective accelerometer-based method to record the static trunk posture in a typical working day of workers in a special school, and to compare the time spent in different static trunk postures between subjects with and without back pain.

\section{Methods \\ Study design}

A cross-sectional design was conducted to record the duration of time spent in different static trunk postures among the teaching staff of a special school for severe handicaps.

\section{Subjects}

All the staff members involved in the classroom routine of a special school for the severe handicaps were invited to join the present study. Subjects were included if they are full time staff and had more than one year of working experience in this school or other special school with similar setting. Subjects were excluded from the present study if they suffered from back pain or injury that was not work-related. Fifty subjects met this selection criteria and 44 of them volunteered to join the study. To ensure the subjects are having the similar exposure to manual lifting at work, the staff members were asked about the total number of lifts that they need to perform each week. The teaching staff members with similar lifting number were included in the current study. A total of 33 subjects (21 teachers, 3 teaching assistants and 9 health care professionals) were recruited for this study. They were divided into two groups: 18 subjects who suffered from bilateral LBP for at least 1-7 days in previous 12 months and severity greater than 1 in the pain scale (0-5), and 15 subjects who did not have back pain in the previous 12 months.

The demographic data of the subjects are summarized in Table 1. T-test revealed no significant differences in mean age, height, body weight, and number of lifts performed each day between the two groups. Nonetheless, there was significant greater proportion of female subjects, and marginal shorter years of working experience in the LBP group.

\section{Ambulatory postural monitoring system}

A bi-axial accelerometer (ADXL202JE, Analog Devices Inc. USA) and a data logger (Pace XR440, Pace Scientific Inc. USA) were attached to a plastic plate which was housed in

Table I: Descriptive statistics of subjects' demographic characteristics

\begin{tabular}{|c|c|c|c|}
\hline Characteristic & $\begin{array}{l}\text { Subjects with LBP } \\
\quad(n=18)\end{array}$ & $\begin{array}{l}\text { Asymptomatic subjects } \\
\qquad(\mathrm{n}=15)\end{array}$ & $\mathrm{p}$-value \\
\hline Mean age (SD) & $33.9(8.2)$ & $38.9(8.0)$ & 0.085 \\
\hline \multicolumn{4}{|l|}{$\operatorname{Sex}(\%)$} \\
\hline Male & $4(22.2 \%)$ & $9(60 \%)$ & \\
\hline Female & $14(77.8 \%)$ & $6(40 \%)$ & 0.03 \\
\hline Mean height (SD) & $161.4 \mathrm{~cm}(7.9)$ & $163.4 \mathrm{~cm}(6.9)$ & 0.448 \\
\hline Mean body weight (SD) & $53.5 \mathrm{~kg}(9.5)$ & $58.5 \mathrm{~kg}(10.2)$ & 0.157 \\
\hline Mean years of working experience & $8.5(4.8)$ & $12.0(5.6)$ & 0.061 \\
\hline Average number of lifts per shift & $16.5(2.9)$ & $15.3(2.3)$ & 0.20 \\
\hline Professions & $\begin{array}{c}\text { Teacher }=1 \mathrm{I} \\
\text { Health care professional }=5 \\
\text { Teaching assistant }=2\end{array}$ & $\begin{array}{c}\text { Teacher }=10 \\
\text { Health care professional }=4 \\
\text { Teaching assistant }=1\end{array}$ & \\
\hline
\end{tabular}


a small aluminum cube. A Velcro soft strap was threaded through the plate so that when it encircled the trunk, its tension could provide extra stability for accelerometer attachment and to minimize the movement between the accelerometer and the underlying skin (Figure 1). The accelerometer was aligned with the spinous processes so that it was not tilted sideways. Since the accelerometer was tilted with respect to the horizontal, the signals in upright standing were taken and this angle of the accelerometer measurement was defined as zero flexion. All measurements were made with respect to this inclination.

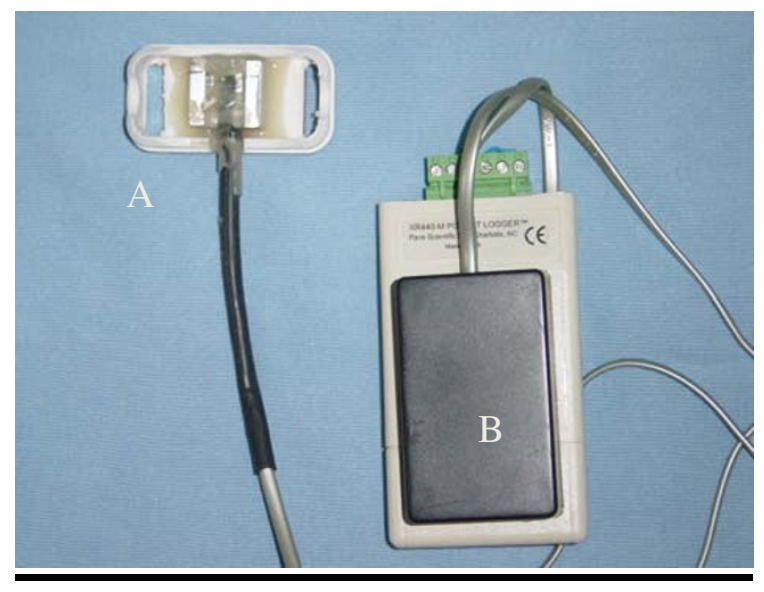

a)

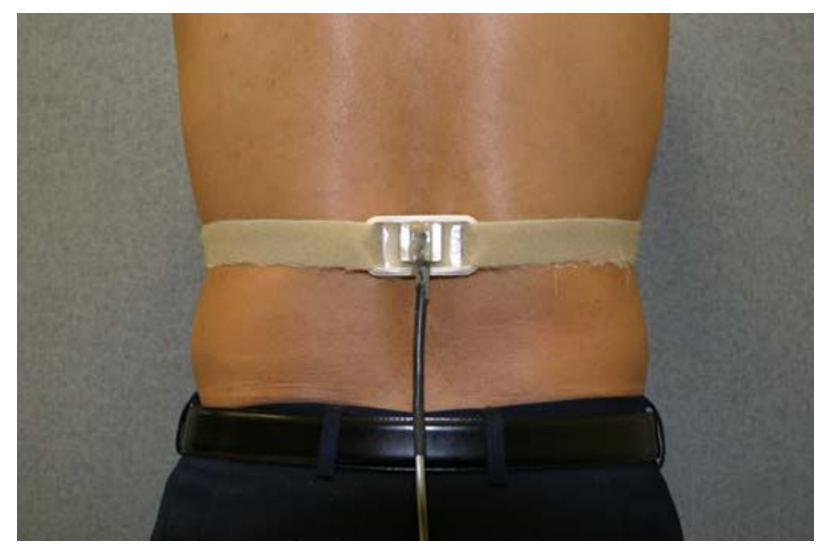

b)

\section{Figure I}

Ambulatory postural monitoring device. a) the accelerometer (A) and the data logger (B). b) Strapping for secure attachment of the accelerometer to the back.

\section{Calibration of the accelerometer and pilot testing}

The accelerometer was calibrated and pilot tested before it was applied to record the static back postures of the workers during a typical work day. The accelerometer was mounted on one arm of a standard goniometer, and was calibrated for static angle measurement by acquiring its signals when positioned at known inclinations from \pm $180^{\circ}$ with $15^{\circ}$ increment. As pure plane of sagittal flexion and extension is not common for human movement, the same procedure of calibration was repeated with the accelerometer side tilted for $15^{\circ}$ and $30^{\circ}$. The averaged difference between the angles of the standard goniometer and the calculated angles from the signals of the accelerometer was small $\left(0.34^{\circ} \pm 0.25^{\circ}\right)$.

In static condition, the sensor detects the vertical inclination relative to gravity $[25,26]$. The vertical inclination $(\theta)$ of the accelerometer is given by

$$
\theta=\tan ^{-1} \frac{a c c_{y}}{a c c_{x}}
$$

where $\mathrm{acc}_{\mathrm{y}}$ is the acceleration in the $\mathrm{y}$-direction and $\mathrm{acc}_{\mathrm{x}}$ the acceleration in the $\mathrm{x}$-direction. As constant acceleration is virtually impossible during normal dynamic activities, conditions will be assumed to be dynamic if the accelerometer detects a time-varying signal and static if the signal is relatively constant. Based on the above assumption, an experimentally determined threshold has to be applied to differentiate the static and dynamic nature of the activities. Activity is defined to be dynamic if the fluctuation of signal is greater than the threshold and static if it is well lower than the threshold [16,26,27]. For this reason, we conducted a pilot test aimed at determining the threshold in defining the static activities from the raw signals of the accelerometer. Three subjects were randomly selected. The accelerometer was attached to the $\mathrm{T}_{12}$ level of the back of the subjects by double-sided adhesive tape. The sampling rate of the data logger was set to be 5 $\mathrm{Hz}$. The subject was then asked to stand upright statically for 1 minute. The signals obtained were regarded as "static standing". After that, eight static postures were performed for 30 seconds (standing with $30^{\circ}, 60^{\circ}$ trunk flexion, sitting with $0^{\circ}, 30^{\circ}, 60^{\circ}$ trunk flexion, kneeling with $0^{\circ}$, $30^{\circ}, 60^{\circ}$ trunk flexion). The raw signals obtained were low-pass filtered with a cutoff frequency of $0.2 \mathrm{~Hz}$ by the second-order Butterworth filter [28]. Thirty seconds of the resultant signals of the $\mathrm{x}$ and $\mathrm{y}$ axes from the known period of "static standing" were extracted. The mean absolute range of the signals was used as the threshold for defining the static posture of that subject.

An algorithm was proposed to define the activity as dynamic in nature if all the absolute differences between the adjacent signals within one-second data were greater 
than the threshold. The threshold was adjusted until the proposed algorithm could correctly detect more than 95\% of time period of the eight static conditions for the three subjects.

The algorithm was then validated by the 3SPACE Fastrak system (Polhemus, Colchester, VT, USA) in discriminating the static and dynamic conditions. The procedures are essentially the same as the setup for the calibration procedures. In brief, the accelerometer and the Fastrak sensor were mounted on one arm of a standard goniometer. The goniometer was either kept in static at various positions or rotated forward and backward for 6 trials. The input signals of both the accelerometer and Fastrak were synchronized and $\mathrm{AD}$ converted to a computer.

The algorithm used for the determination of the onset of dynamic conditions was compared to the signals from the Fastrak sensor. The absolute differences between the accelerometer and Fastrak in detecting the time of onset and stop of the six dynamic conditions were calculated and averaged. It was found that both the accelerometer and Fastrak system could consistently detect the various static and dynamic conditions and the averaged difference between the accelerometer and Fastrak in detecting the time of onset and stop was small $(0.69 \pm 0.57 \mathrm{~s})$. The accelerometer was considered to be sufficiently accurate for detecting static and dynamic postures.

The Fastrak was also used to validate the angles derived from the accelerometer. Figure 2 shows a plot of the two sets of inclination angles during various static positions. The data was fitted with a best straight line (slope $=0.99$, intercept $=0.2^{\circ}$ ), with a correlation coefficient of 0.99 . This indicated that there was very little offset error in the accelerometer measurement, and there was very strong agreement between the two data sets.

\section{In-field trunk posture measurement}

The accelerometer was attached at $\mathrm{T}_{12}$ level by using the double-sided adhesive tape. Before the attachment, the skin was cleaned by cotton wool soaked with $75 \%$ alcohol. The position of the accelerometer was then marked on the back by using the black ball pen. The position of the accelerometer was further secured by asking the subjects to fasten the strapping and apply the soft corset clothing over the trunk himself. With the tension of the strapping and the soft corset clothing, the stability of accelerometer on the back would be enhanced and excessive movement of the accelerometer on the back could be prevented. The subject were also asked to check if there was any discomfort or hindering of trunk movement by the strapping and soft corset so that he could not perform the trunk movement "naturally".

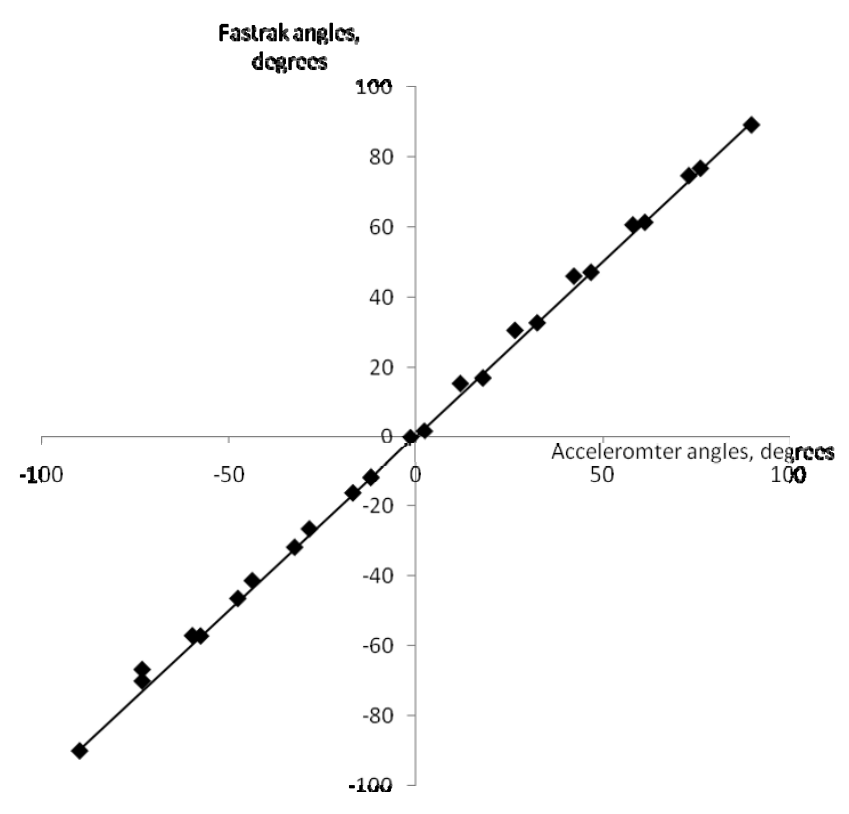

Figure 2

Plot of fastrak angles against angles derived from the accelerometers with the best straight line fit.

Prior to the experiment, subjects were asked to stand still for 1 minute. Signals recorded were used to determine the threshold of static posture for that subject. It is important to note that the threshold should be individually determined because different people may adopt different body sway during their static activities. The subject was then asked to resume his work in normal pace. Postural data was collected during the morning ( 3 hours) and afternoon ( 3 hours) period of the subject at a sampling rate of $5 \mathrm{~Hz}$. By the end of the working day, the subject was asked to stand straight statically again for 1 minute and this postural data was used to compare with that of the initial standing position to ensure there was no difference between two data set. Furthermore, the accelerometers were employed as inclinometers when the subject was detected to have adopted a static posture. The angle of trunk inclination was calculated from the signals of the accelerometers as described above.

The accelerometer signals were checked in upright standing after the experiment. The accelerometer would detect a proportion of acceleration due to gravity $(\mathrm{g})$ according to its inclination with respect to gravity. If the accelerometers had been moved due to skin or soft tissue deformation or insecure attachment, the accelerometer signal in upright standing would be different after the experiment. So checking the signal in upright standing would allow us 
to determine if the accelerometer had moved away due to the error.

\section{Data analysis}

The percentage of time spent in static trunk posture was calculated by dividing the time spent in static trunk posture by the total time of postural data collection of the whole working day. Moreover, the percentage of time spent in static trunk posture was further categorized into four groups of trunk flexion, namely (1) $\theta \leq 10^{\circ}$, (2) $10^{\circ}<\theta \leq 30^{\circ}$, (3) $30^{\circ}<\theta \leq 60^{\circ}$, (4) $\theta>60^{\circ}$, where $\theta$ is the inclination angle.

Statistical analyses were conducted using the Statistical Package for the Social Science (Version 16 SPSS Inc. Illinois USA). As there was a greater proportion of female subjects $(p=0.03)$ and shorter years of working experience $(p=0.061)$ in the LBP group, gender and working experience were employed as covariates in the analysis. Two way analysis of covariance (ANCOVA) was used to analyze the effects of group (back pain vs asymptomatic) and posture (the four posture categories i.e. $\theta \leq 10^{\circ}$, $10^{\circ}<\theta \leq 30^{\circ}, 30^{\circ}<\theta \leq 60^{\circ}, \theta>60^{\circ}$ ) on the percentage of time spent in these postures. The interaction between the variables group and posture was examined, and post-hoc analysis was performed if the independent variables were found to be significant $(\mathrm{p}<0.05)$.

\section{Results \\ In-field trunk posture measurement}

Figure 3 shows the raw data of the resultant accelerometer signals against time in one of the subjects. It clearly demonstrates that using the algorithm described above, the accelerometer was able to effectively discriminate static and dynamic conditions. The period when signals exceeded the threshold (shown as a dotted line with a value of 1) was defined as dynamic activities, whereas static conditions was denoted by the dotted line with a value of 0 .

The angles of trunk inclination of the known period of static standing before and after the work for all of the subjects were compared by intra-class correlation coefficient (ICC). High correlation was shown between the two trials of static standing $[\operatorname{ICC}(1,1)=0.92]$. Moreover, the accelerometer did not move away from the skin markings after the whole day work for all of the subjects. Thus, the accelerometer was fixed properly on the back of the subjects during the whole day work without any unwanted movement between the skin and the accelerometer.

The percentages of time spent in static trunk posture for the two groups of subjects are summarized in Figure 4. ANCOVA revealed a significant difference in percentage of time spent in static trunk posture between the 2 groups and interaction between the group and posture $(\mathrm{p}<0.05)$. Subjects with low back pain spent longer time in static trunk posture than the group without LBP. Post hoc anal-

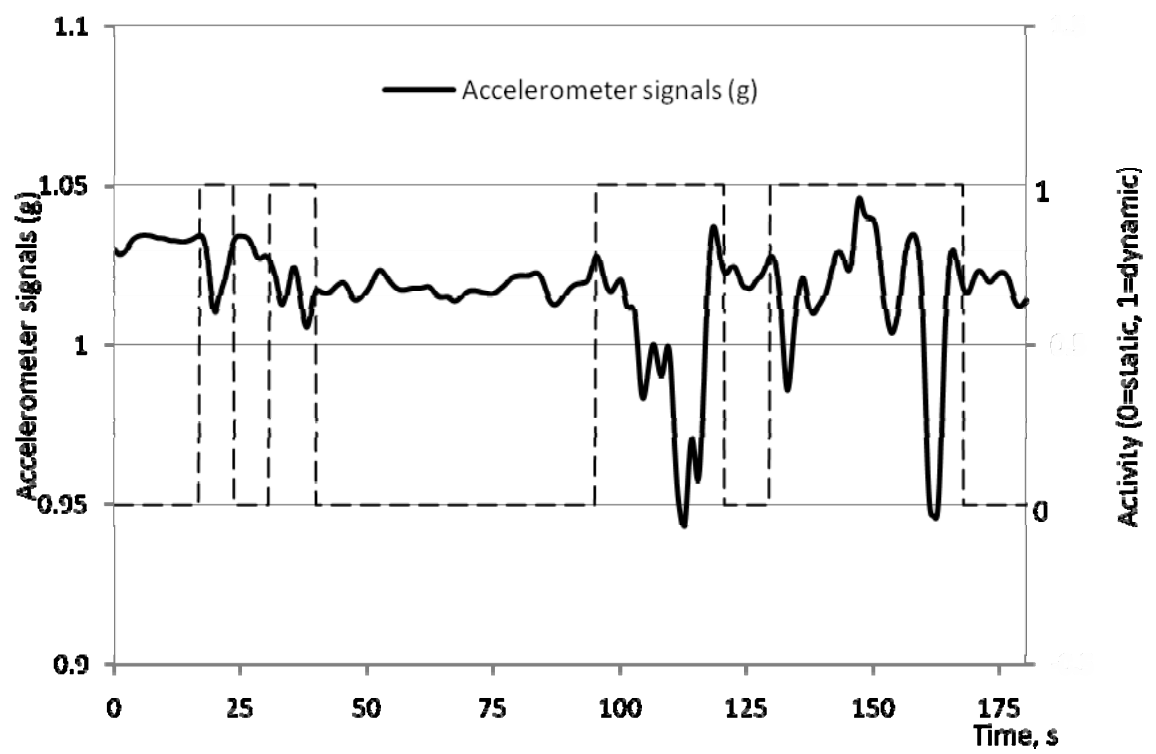

\section{Figure 3}

Plot of the resultant accelerometer signals against time. The period when the signals exceed the threshold (shown as dotted line with a value of I) was defined as dynamic activities. 


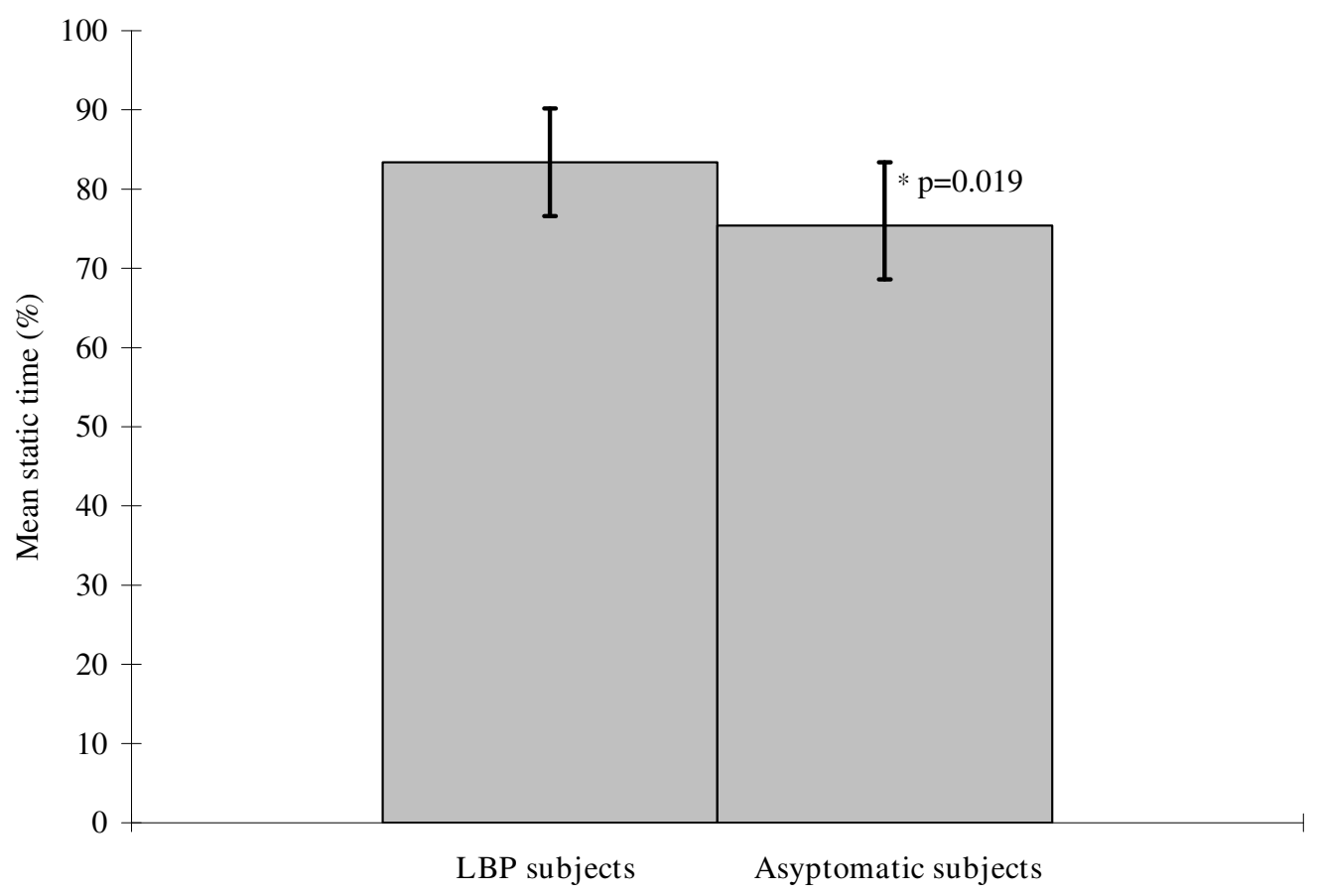

\section{Figure 4}

Percentage of time spent in static back posture for the LBP and asymptomatic subjects.

ysis revealed significant differences between the 2 groups in percentage of time spent in all four trunk posture categories $(\mathrm{p}<0.05)$ (Table 2$)$. The results are summarized in Table 2. LBP subjects spent significantly less time in posture with flexion of less $10^{\circ}$ and more time in the other three posture categories with flexion of more than $10^{\circ}(\mathrm{p}$ $<0.05)$.

\section{Discussion}

\section{Tracking spinal posture in the workplace}

It is generally accepted that cumulative spinal loading is one of the causative factors contributed to LBP $[29,30]$. Thus, it is important to accurately record the cumulative effects of static postures at the workplace such that appropriate intervention strategies can be introduced. This study employs a new, innovative method to track static posture using accelerometers. The results of the current study indicated that the accelerometer-based method is accurate and feasible at the workplace. It can record the temporal characteristics and the cumulative effects of the static spinal movement at the workplace over an extended period of time. This is superior to the questionnaires or observation methods commonly used in the field which only provide a subjective estimate of time spent in work postures. The accelerometers employed in this study are small, light and inexpensive, and are ideal for tracking spinal posture in the workplace. Future study should explore how these sensors can be used in other applications and work environments.

Table 2: Duration and percentage of time in static back posture for LBP subjects and asymptomatic subjects in four trunk flexion categories

\begin{tabular}{|c|c|c|c|c|c|}
\hline \multirow[b]{2}{*}{$\leq 10^{\circ}$ flexion } & \multicolumn{2}{|c|}{$\begin{array}{l}\text { Subjects with LBP } \\
\quad(n=18)\end{array}$} & \multicolumn{2}{|c|}{$\begin{array}{l}\text { Asymptomatic subjects } \\
\qquad(\mathrm{n}=15)\end{array}$} & \multirow{2}{*}{$\begin{array}{l}\text { P-value } \\
0.002\end{array}$} \\
\hline & $3.4 \mathrm{I} \pm 0.83 \mathrm{hr}$ & $56.9 \pm 13.7 \%$ & $4.6 \mathrm{I} \pm 0.93 \mathrm{hr}$ & $76.8 \pm 15.6 \%$ & \\
\hline $11^{\circ}-30^{\circ}$ flexion & $1.86 \pm 0.59 \mathrm{hr}$ & $31.0 \pm 9.9 \%$ & $1.09 \pm 0.74 \mathrm{hr}$ & $18.2 \pm 12.4 \%$ & 0.012 \\
\hline $31^{\circ}-60^{\circ}$ flexion & $0.69 \pm 0.34 \mathrm{hr}$ & $10.2 \pm 5.7 \%$ & $0.25 \pm 0.18 \mathrm{hr}$ & $4.2 \pm 3.0 \%$ & 0.002 \\
\hline$\geq 61^{\circ}$ flexion & $0.11 \pm 0.12 \mathrm{hr}$ & $1.9 \pm 2.0 \%$ & $0.03 \pm 0.02 \mathrm{hr}$ & $0.5 \pm 0.4 \%$ & 0.012 \\
\hline Total & $6 \mathrm{hr}$ & $100 \%$ & $6 \mathrm{hr}$ & $100 \%$ & \\
\hline
\end{tabular}




\section{The association between LBP and static trunk postures at work}

In the present study, staff with LBP spent significantly longer percentage of time in static trunk posture with more trunk flexion when compared to staff without LBP. It thus appears that an increase in risk of back pain may be associated with long period of sustained stooped posture. Indeed, similar results had been shown in other studies. For instance, Christensen et al. [31] applied both questionnaires and observation method for addressing the reason of occurrence of LBP among the workers in the Danish wood and furniture industry. Their results indicated that manual material handling and prolonged static trunk flexion for more than 10 seconds were the main reasons for the workers to suffer from LBP. Similarly, Hoogendoorn et al. [9] investigated the relationships between trunk posture and lifting at work and the occurrence of LBP by video-taping the work postures of the blue- and white-collar workers. They showed that the workers had higher risk of getting LBP when they worked with the trunk in a minimum of $60^{\circ}$ flexion for more than $5 \%$ of their working time $(\mathrm{RR}=1.5)$. In a three year prospective cohort study, Hoogendoorn et al. [4] found an increase in risk $(\mathrm{OR}=1.4$ ) for the workers to get low back pain when there was an increase in time of exposure to heavy load and flexed trunk posture. In a ten year longitudinal study, Marras et al. [3] showed that the reduction of the maximal sagittal trunk flexion of the workers by the introduction of lift tables could significantly decrease the low back disorder incidence rate. Clearly, a sustained posture of stooping is a major factor associated with the occurrence of LBP.

As the staff in the special school is required to adopt a flexed trunk posture on the ground level for performing mat activities for the students, the external flexion moment of the trunk is inevitably counteracted by the activation of the lumbar extensors and the passive structures of the spine. Such muscle contraction may further increase when there is external loading at the trunk when workers are required to support the severely handicapped students during various functional training. Constant contraction of the erector spinae during static lumbar flexion, even at the level of $2 \%$ of MVC would compromise the capillary blood flow to the erector spinae, and predispose the muscle to fatigue and injuries [14,32]. Callaghan and McGill [32] pointed out that as a result of fatigue, LBP may result from stress accumulation of the passive structures that stimulates the nociceptors responses [12] and the lactate accumulation over the erector spinae due to the effect of deoxygenation of the muscles [14]. Prolonged lumbar flexion will also lead to creep and other viscoelastic responses [11] so that spinal tissues are subjected to higher strains, and the risks of injuries may be increased.
The results of the present investigation and the previous studies support the conclusion that teaching members of this special school are at increased risk of getting low back pain when they spend prolonged period of time in static trunk flexion during work. Frequent postural change and awareness of trunk posture during mat activities are highly recommended for relieving the stress of passive and active structures of the low back resulted from constant loading of the static trunk posture. Rest activities such as standing up from stooping and walking for a short distance are suggested to promote the cyclic muscular contraction and relaxation that facilitate the nourishment of spinal tissues and provide periodic rest to the muscles [32].

It should be noted the present study only examined the static trunk postures of the teaching staff. The effects of external loading onto the spine were not examined. However, giving the fact that the subjects performed similar manual handling activities at work, the effects of external load should be common to both the symptomatic and asymptomatic group. It is also impossible to use accelerometers to record dynamic trunk orientation and this will require other inertial sensors such as gyroscopes. Further study is suggested to include the measurement of dynamic trunk motions of the subjects so as to examine the role of dynamic movements in back pain. Moreover, a selfreported work-task diary is suggested to record the work task of subjects so that the tasks with high risks of injuries can be specifically identified and a more specific ergonomic intervention can be suggested.

\section{Conclusion}

An innovative method has been developed for tracking spinal posture. This study demonstrated that the accelerometer-based method is highly sensitive in differentiating the static and dynamic nature of activities. It is highly accurate in recording static spinal posture as well as the time spent in these postures. The sensors are also small in size, light in weight and inexpensive, and will be the ideal tool for continuous monitoring of trunk posture in ergonomic and clinical assessments.

It was shown that teaching staff with LBP spent significantly longer percentage of time in static trunk flexion (more than $10^{\circ}$ ) than those without LBP. It is concluded that back pain is associated with prolonged periods of time in static trunk flexion during work. Frequent postural change and awareness of trunk posture are recommended for relieving muscle fatigue and tissue strains due to constant loading of the spine.

\section{Competing interests}

The authors declare that they have no competing interests. 


\section{Authors' contributions}

KCHW, RYWL, and SSY participated in conceiving the study design, data analyses and interpretation of the data. KCHW contributed substantially in the data collection, and drafted the manuscript. RYWL and SSY have been involved in critically revising the manuscript for important intellectual input. All authors read and approved the final manuscript.

\section{Acknowledgements}

The authors would like to thank all the teachers, teaching assistants and health care professionals of the special school who volunteered in this study.

\section{References}

I. Brulin C, Gerdle B, Granlund B, Höög J, Knutson A, Sundelin G: Physical and psychosocial work-related risk factors associated with musculoskeletal symptoms among home care personnel. Scand J Caring Sci 1998, I 2: 104-II 0.

2. Milburn PD, Barrett RS: Lumbosacral loads in bedmaking. Appl Ergon 1999, 30:263-273.

3. Marras WS, Allread WG, Burr DL, Fathallah FA: Prospective validation of a low-back disorder risk model and assessment of ergonomic interventions associated with manual materials handling tasks. Ergonomics 2000, 43(I I): | 1866-1886.

4. Hoogendoorn WE, Bongers PM, de Vet HCW, Twisk JWR, van Mechelen W, Bouter LM: Comparison of two different approaches for the analysis of data from a prospective cohort study: an application to work related risk factors for low back pain. Occup Environ Med 2002, 59:459-465.

5. Friedrich M, Cermak T, Heiller I: Spinal troubles in sewage workers: epidemiological data and work disability due to low back pain. Int Arch Occup Environ Health 2000, 73:245-254.

6. Seidler A, Bolm-Audorff U, Heiskel H, Henkel N, Roth-Küver B, Kaiser U, Bickeböller R, Willingstorfer WJ, Beck W, Elsner G: The role of cumulative physical work load in lumbar spine disease: risk factors for lumbar osteochondrosis and spondylosis associated with chronic complaints. Occup Environ Med 200I, 58:735-746.

7. Yip YB: A study of work-stress, patient handling activities and the risk of low back pain among nurses in Hong Kong. J Adv Nurs 200I, 36(6):794-804.

8. Holmström EB, Lindell J, Moritz U: Low back pain and neck/ shoulder pain in construction workers: Occupational workload and psychosocial risk factors. Part I: Relationship to low back pain. Spine 1992, 17(6):663-67I.

9. Hoogendoorn WE, Bongers PM, de Vet HCW, Douwes M, Koes BW, Miedema MC, Ariëns GAM, Bouter LM: Flexion and rotation of the trunk and lifting at work are risk factors for low back pain. Spine 2000, 25(23):3087-3092.

10. Williams M, Solomonow M, Zhou BH, Baratta RV, Harris M: Multifidus spasms elicited by prolonged lumbar flexion. Spine 2000 , 25(22):2916-2924.

II. McGill SM, Brown S: Creep response of the lumbar spine to prolonged full flexion. Clin Biomech 1992, 7:43-46.

12. Callaghan JP, Dunk NM: Examination of the flexion relaxation phenomenon in erector spinae muscles during short duration slumped sitting. Clin Biomech 2002, 17:353-360.

13. Solomonow M, Baratta RV, Banks A, Freudenberger C, Zhou BH: Flexion-relaxation response to static lumbar flexion in males and females. Clin Biomech 2003, 1 8:273-279.

14. McGill SM, Hughson RL, Parks K: Lumbar erector spinae oxygenation during prolonged contractions: implications for prolonged work. Ergonomics 2000, 43(4):486-493.

15. Wilke HJ, Neef P, Caimi M, Hoogland T, Claes LE: New in vivo measurements of pressures in the intervertebral disc in daily life. Spine 1999, 24(8):755-762.

16. Bussmann JBJ, Tulen JHM, van Herel ECG, Stam HJ: Quantification of physical activities by means of ambulatory accelerometry: A validation study. Psychophysiology 1998, 35:488-496.
17. Kilbom $\AA$ : Assessment of physical exposure in relation to work-related musculoskeletal disorders-what information can be obtained from systematic observations? Scand J Work Environ Health 1994, 20 Spec No:30-45.

18. Hansson GÅ, Balogh I, Byström JU, Ohlsson K, Nordander C, Asterland P, Sjölander S, Rylander L, Winkel J, Skerfving S, Malmö ShoulderNeck Study Group: Questionnaire versus direct technical measurements in assessing postures and movements of the head, upper back, arms and hands. Scand J Work Environ Health 200I, 27(I):30-40

19. Saur PM, Ensink FB, Frese K, Seeger D, Hildebrandt J: Lumbar range of motion: reliability and validity of the inclinometer technique in the clinical measurement of trunk flexibility. Spine 1996, 2 I (I I): 1332-1338.

20. $\mathrm{Ng} J \mathrm{KF}$, Kippers V, Richardson CA, Parnianpour M: Range of motion and lordosis of the lumbar spine: reliability of measurement and normative values. Spine 200I, 26(I):53-60.

2I. Paquet VL, Punnett L, Buchholz B: Validity of fixed-interval observations for postural assessment in construction work. Appl Ergon 200I, 32(3):215-224.

22. Bernmark E, Wiktorin C: A triaxial accelerometer for measuring arm movements. Appl Ergon 2002, 33:541-547.

23. van Dieën $\mathrm{JH}$, Jansen SMA, Housheer AF: Differences in low back load between kneeling and seated working at ground level. Appl Ergon 1997, 28(5/6):355-363.

24. Grant KA, Habes DJ, Tepper AL: Work activities and musculoskeletal complaints among preschool workers. Appl Ergon 1995, 26(6):405-410.

25. Kemp B, Janssen AJMW, Kamp B van der: Body position can be monitored in 3D using miniature accelerometers and earthmagnetic field sensors. Electroenceph Clin Neurophysiol 1998, 109:484-488.

26. Lötters JC, Schipper J, Veltink PH, Olthuis W, Bergveld P: Procedure for in-use calibration of triaxial accelerometers in medical applications. ensors and Actuators A 1998, 68:221-228.

27. Veltink PH, Bussmann HBJ, de Vries W, Martens WLJ, Van Lummel RC: Detection of static and dynamic activities using uniaxial accelerometers. IEEE Trans Rehab Eng 1996, 4(4):375-385.

28. Winter DA: Biomechanics and motor control of human movement Volume Ch 2. Hoboken, N.J.: John Wiley \& Sons; 2005.

29. Waters T, Yeung S, Genaidy A, Callaghan J, Barriera-Viruet H, Deddens J: Cumulative spinal loading exposure methods for manual material handling tasks Part I: Is cumulative spinal loading associated with lower back disorders? Theoretical Issues in Ergonomic Sciences 2006, 7: II 3-130.

30. Waters T, Yeung S, Genaidy A, Callaghan J, Barriera-Viruet H, Kumar $S$ : Cumulative spinal loading exposure methods for manual material handling tasks. Part 2: methodological issues and applicability for use in epidemiological studies. Theoretical Issues in Ergonomic Sciences 2006, 7:131-148.

31. Christensen H, Pedersen MB, Sjøgaard G: A national cross-sectional study in the Danish wood and furniture industry on working postures and manual materials handling. Ergonomics 1995, 38(4):793-805

32. Callaghan JP, McGill SM: Low back joint loading and kinematics during standing and unsupported sitting. Ergonomics 200I, 44(3):280-294.

\section{Pre-publication history}

The pre-publication history for this paper can be accessed here:

\section{http://www.biomedcentral.com/1471-2474/10/43/pre} pub 